\title{
Fine-mapping of two differentiated thyroid carcinoma susceptibility loci at 2q35 and 8p12 in Europeans, Melanesians and Polynesians
}

\author{
Julie Guibon ${ }^{1,2}$, Pierre-Emmanuel Sugier ${ }^{1}$, Om Kulkarni ${ }^{3}$, Mojgan Karimi ${ }^{1}$, \\ Delphine Bacq-Daian ${ }^{3}$, Céline Besse ${ }^{3}$, Anne Boland ${ }^{3}$, Elisabeth Adjadj ${ }^{4}$, Frédérique \\ Rachédi ${ }^{5}$, Carole Rubino ${ }^{4}$, Constance Xhaard ${ }^{4,6}$, Claire Mulot ${ }^{7}$, Pierre Laurent- \\ Puig7, Anne-Valérie Guizard ${ }^{8,9}$, Claire Schvartz ${ }^{10}$, Rosa Maria Ortiz ${ }^{11}$, Yan Ren $^{4}$, \\ Evgenia Ostroumova ${ }^{12}$, Jean-François Deleuze ${ }^{3}$, Marie-Christine Boutron-Ruault ${ }^{1}$, \\ Ausrele Kesminiene ${ }^{12}$, Florent De Vathaire ${ }^{4}$, Pascal Guénel ${ }^{1}$, Fabienne Lesueur ${ }^{2, *}$ \\ and Thérèse Truong ${ }^{1, *}$

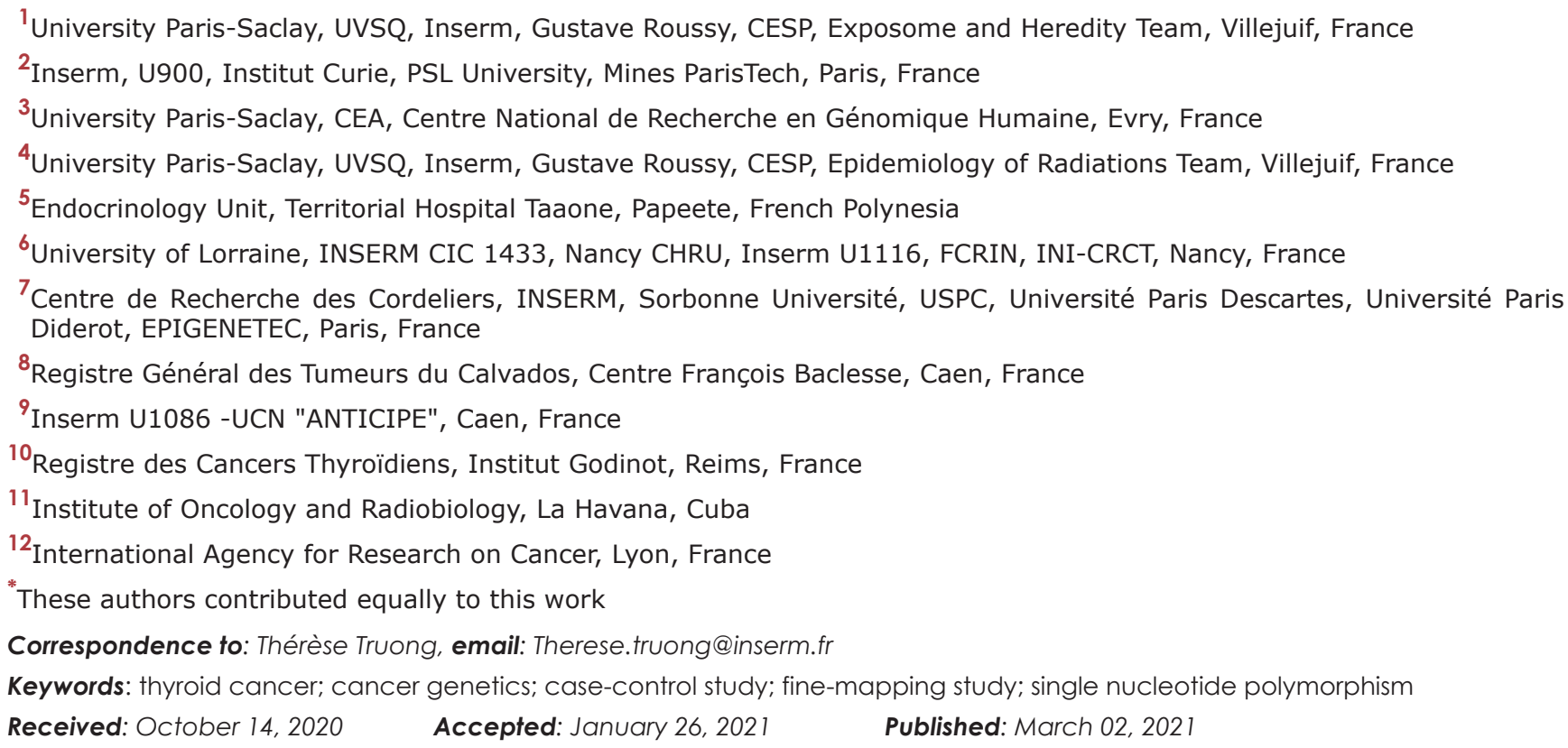

Copyright: @ 2021 Guibon et al. This is an open access article distributed under the terms of the Creative Commons Attribution License (CC BY 3.0), which permits unrestricted use, distribution, and reproduction in any medium, provided the original author and source are credited.

\section{ABSTRACT}

Differentiated thyroid carcinoma (DTC) incidence is characterized by wide ethnic and geographic variations, with high incidence rates observed in Oceanian populations. Genome-wide association studies (GWAS) identified mainly four DTC susceptibility loci at 9 q22.33, 14q13.3, 2q35 and 8p12. Here we performed finemapping of the 2q35 and 8p12 loci in the population of the EPITHYR consortium that includes Europeans, Melanesians and Polynesians to identify likely causal variants for DTC risk. We conducted a colocalization analysis using eQTLs data to determine the SNPs with the highest probability of causality.

At 2q35, we highlighted rs16857609 located in DIRC3. This SNP has a high probability of causality in the three populations, and a significant association in Europeans $\left(O R=1.4, p=1.9 \times 10^{-10}\right)$. It is also associated with expression of DIRC3 and of the nearby gene IGFBP5 in thyroid tumour cells. At 8p12, we identified rs7844425 which was significantly associated with DTC in Europeans (OR $=1.32, p$ $=7.6 \times 10^{-8}$ ) and rs2439304, which was highlighted by the colocalization analysis but only moderately associated with DTC in our dataset $(O R=1.2, p=0.001)$. These SNPs are linked to the expression of NRG1 in thyroid tissue. 


\section{Hence, our study identified novel variants at $2 q 35$ and $8 p 12$ to be prioritized for further functional studies.}

\section{INTRODUCTION}

Thyroid cancer (TC) is the most common endocrine malignancy. Its incidence has been rising over the past few decades and varies considerably around the world. Elevated incidence was reported in some Pacific islands such as French Polynesia and New-Caledonia, two French territories, with estimated incidence rates in 2018 being $27.7 / 100,000$ and $25.6 / 100,000$ person-years (PY) in women and 6.5/100 000 and 7.6/100 000 PY in men [1], respectively. Ethnic differences in incidence have also been reported in New-Caledonia with higher rates among Melanesians than in other ethnic groups [2]. In metropolitan France, the incidence rates were 20.9/100,000 in women and 5.7/100,000 PY in men in 2018 [1].

Papillary thyroid carcinoma (PTC) and follicular thyroid carcinoma (FTC) are the most frequent subtypes of differentiated thyroid carcinoma (DTC), and represent about $90 \%$ of all TC. Apart from exposure to ionizing radiation during childhood which is the only wellestablished risk factor, DTC risk has been consistently associated with obesity [3]. Other risk factors such as deficiency or excess of iodine levels [4] or some hormonal and reproductive factors are also suspected [5]. Moreover, familial risk for TC is among the highest of all cancers [6], suggesting a role of genetic risk factors. Six previous genome-wide association studies (GWAS) of DTC conducted in European populations [7-12] and a GWAS conducted in the Asian population [13] allowed the identification of several DTC susceptibility loci, with the strongest associations being reported at $9 \mathrm{q} 22.33,14 \mathrm{q} 13.3$, $2 q 35$ and 8 p12. Recently, a meta-analysis including 3,001 DTC cases and 287,500 controls of European descent confirmed these findings and yielded five additional loci associated to DTC at 1q42.2, 3q26.2, 5q22.1, 10q24.33, $15 \mathrm{q} 22.33$ that were not replicated yet [12]. We recently conducted a GWAS in EPITHYR that confirmed the susceptibility loci at 9q22.33, 14q13.3, 2q 35 and 8p12, and suggested novel signals at 1p31.3 and 16q23.2 [14].

Fine-mapping studies have already been conducted to identify potential causal variants at loci $9 \mathrm{q} 22.33$ and $14 q 13.3[15,16]$. These variants were subsequently widely replicated, and functional studies were performed to support their role in the aetiology of DTC. To our knowledge, no fine-mapping analyses have been performed so far at $2 \mathrm{q} 35,8 \mathrm{p} 12$ or other DTC susceptibility loci.

Rs966423 at $2 \mathrm{q} 35$ and rs2439302 at 8p12 were first identified in GWAS to investigate genetic factors associated with thyroid stimulating hormone (TSH) levels. In the study conducted in Iceland on 27,758 individuals with available circulating TSH measurements [9], the identified SNPs were also found to be associated with DTC risk [9]. Subsequently, these variants were replicated in other populations of European [9, 12] and Asian [13] ancestry.

At locus 2q35, several other variants were also highlighted by GWAS to be associated with DTC in populations of European ancestry. Rs6759952 was reported in GWAS conducted on 3648 DTC cases and 4,224 controls from Italy [10], while a recent metaanalysis of GWAS reported the strongest association with variant rs 11693806 at this locus [12]. In European populations, both rs11693806 and rs6759952 were moderately correlated with rs 966423 (with $\mathrm{r}^{2}=0.47$ and $\mathrm{r}^{2}$ $=0.74$, respectively) $[10,12]$. In Korea, a GWAS identified two additional SNPs at 2q35, namely rs12990503 and rs1549738, associated with DTC risk [13]. According to 1000Genomes, rs 12990503 was highly correlated $\left(\mathrm{r}^{2}=\right.$ 0.97) with rs11693806 in East Asian populations while rs1549738 was moderately correlated with the GWAS SNP rs966423 $\left(r^{2}=0.41\right)$. Most of the risk variants at this locus are located within the DIRC3 (disrupted renal cancer 3) gene. Although this gene is presumed to have a tumour suppressor activity [10], no functional studies have been performed so far to validate this hypothesis. In 2012, Gudmundsson et al. hypothesized that DIRC3 variants by reducing TSH levels, may lead to reduced differentiation of the thyroid epithelium, and consequent predisposition to malignant transformation [9].

At locus 8p12, only rs2439302 and rs2466076 have been associated with DTC risk in European populations, and the two SNPs were reported as strongly correlated $\left(\mathrm{r}^{2}=0.94\right.$ in Icelandic population) [12]. The Korean GWAS highlighted two other DTC risk variants, namely rs6996585 and rs12542743 [13], with rs6996585 being moderately correlated with the GWAS SNP rs2439302 $\left(\mathrm{r}^{2}=0.67\right.$ in Asian population of $\left.1000 \mathrm{Genomes}\right)$. All associated variants at this locus were located within the NRG1 gene, which encodes neuregulin 1, a signalling protein that mediates cell-cell interactions and plays a role in the development of multiple organ systems.

Altogether, several DTC risk variants have been identified at $2 \mathrm{q} 35$ and $8 \mathrm{p} 12$ but few of them have been further explored with fine-mapping or functional studies to identify the causal ones. Here, our goal was to perform a fine-mapping analysis of these two loci using genotypic data from the EPITHYR GWAS involving Europeans, Polynesians and Melanesians, three populations with distinguishable genetic architecture, and functional annotations to highlight the potential causal variants. 


\section{RESULTS}

We used data from EPITHYR consortium in which GWAS data was available for 1,855 cases and 2,321 controls of Europeans, Polynesians and Melanesians ancestries. The distribution of the study participants by study, age groups, sex and TC histology is presented in Table 1 for each ethnic group. Women represented more than $82 \%$ of cases in each ethnic group. As expected, the majority of cases were PTC $(>82 \%$ of cases in each ethnic group). The number of SNPs included in the current analysis at loci 2q35 and 8p12 are provided for each ethnic group in Supplementary Table 1.

\section{Locus $2 q 35$}

\section{Fine-mapping}

In Europeans, among the 2,682 analysed SNPs at $2 \mathrm{q} 35,42$ SNPs were associated with DTC risk at $p<5 \times 10^{-8}$ (Supplementary Table 2). We replicated the associations from previous GWAS with SNPs rs6579952 $\left(\mathrm{OR}=1.26, p=2.9 \times 10^{-10}\right)$, rs11693806 $\left(\mathrm{OR}=1.43, p=1.1 \times 10^{-10}\right), \operatorname{rs} 1382435(\mathrm{OR}=1.32, p$ $\left.=1.2 \times 10^{-7}\right)$ and $\mathrm{rs} 966423\left(\mathrm{OR}=1.27, p=2.6 \times 10^{-}\right.$ $\left.{ }^{6}\right)$ (Supplementary Table 3). However, in our sample, the most significant association was observed for the genotyped SNP rs57481445 $\left(\mathrm{OR}=1.43, p=8.6 \times 10^{-11}\right)$ (Figure 1A and Supplementary Table 2). In Europeans, this variant was strongly correlated with rs11693806 $\left(\mathrm{r}^{2}\right.$ $=0.98$ ) and 38 of the most significantly associated SNPs (Supplementary Table 4). No significant additional signal was observed after conditioning the association test on the top SNP rs57481445 (Figure 1B), suggesting that any residual association signal due to some additional independent SNPs was unlikely within the region.

In Melanesians and Polynesians, no SNP reached the standard genome-wide significance $P$-value threshold of $5 \times 10^{-8}$ (Figure 1C and 1D) and the four previously reported associated SNPs in European GWAS, rs6759952, rs1169s3806, rs1382435 and rs966423, were not replicated here (Supplementary Table 3). Unlike the European population, very high effect allele frequencies were observed for these SNPs. The most significant SNPs in this locus were rs7575155 in Melanesians $(\mathrm{OR}=2.42$, $\left.p=1.1 \times 10^{-2}\right)$ and $\mathrm{rs} 60862033\left(\mathrm{OR}=6.3, p=1.8 \times 10^{-3}\right)$ in Polynesians (Figure 1C and 1D).

The LD patterns at $2 \mathrm{q} 35$ in the three ethnic groups were slightly similar with LD blocks of stronger LD between SNPs in Melanesians and Polynesians (Supplementary Figure 1). The identified SNPs rs57481445, rs16857609 and rs3821098 were located within the same LD block in the three populations.

In the pooled analysis, the most significant association at locus $2 \mathrm{q} 35$ was observed for the genotyped SNP rs3821098 $\left(\mathrm{OR}=1.44, p=1.6 \times 10^{-12}\right)$ (Supplementary Figure 2A) which is in strongly correlated to rs57481445 $\left(r^{2}>0.87\right.$ in the three populations). After conditioning on the top SNP rs3821098, no additional SNP was highlighted (Supplementary Figure 2B). Of note, although only imputed SNPs with an imputation quality score above 0.3 were kept in the analyses, all highlighted variants had info scores above 0.9 .

\section{Functional data}

The colocalization analysis using eQTL data (Supplementary Figure 3A) highlighted two intronic DIRC3 variants, namely rs16857609 (PP of causality = $0.41)$ and rs12990503 (PP of causality $=0.39)$ (Table 2 and Supplementary Figure 3B). These two SNPs were highly correlated to rs57481445 $\left(\mathrm{r}^{2}>0.9\right)$ and also strongly associated with the expression of DIRC3 and IGFBP5 (insulin growth factor binding protein 5) in thyroid tumour cells, according to TCGA data [17].

In Melanesians and Polynesians, the colocalization analysis also gave the highest PP of causality values for the same two SNPs identified in Europeans: rs16857609 with a $\mathrm{PP}_{\text {Melanesians }}=0.22$ and $\mathrm{PP}_{\text {Polynesians }}=0.32$, and rs12990503 with a $\mathrm{PP}_{\text {Melanesians }}=0.39$ and $\mathrm{PP}_{\text {Polynesians }}=0.35$ (Supplementary Figure 3C and 3D). Rs16857609 and rs12990503 were strongly correlated in the three ethnic groups with $\mathrm{r}^{2}>0.88$.

Rs57481445 and rs16857609, very close to each other $(<240$ bases $)$ and located within the same LD block in the three populations (Supplementary Figure 1), are mostly located within the same functional annotation sites. They are both located within sites of histone modification, notably sites of epigenetic acetylation and methylation on histone H3 protein subunit. They are also located within markers of enhancer chromatin state and actively transcribed chromatin states, which are active states associated with genes' expression level in adipose tissue and adipocytes. Furthermore, rs16857609 is located within sites of DNase involving in three different cellular types (ovary, fetal heart and pluripotent cells). Rs12990503 is located within markers of chromatin state in adipocytes which are low or weak transcription site of gene.

\section{Stratified analyses}

We performed subgroup analyses on rs16857609 in strong LD with the top SNP rs57481445 in the three ethnic groups because it was the most interesting candidate SNP with regards to its functional annotation data. Stratified analyses were performed by study, sex, age group, TC histology and size of papillary carcinoma (Figure 3A). Heterogeneity was observed when stratifying by tumour histology (with $\mathrm{I}^{2}=99.2 \%, p<10^{-4}$ ). We found that carriers of the risk allele [T] have a higher risk of developing PTC rather than FTC. No heterogeneity was detected in Melanesians and Polynesians. Although association was non-significant in these two populations, 
Table 1: Characteristics of subjects from EPITHYR included in the analyses by ethnic group

\begin{tabular}{|c|c|c|c|c|c|c|c|c|c|c|c|c|}
\hline & \multicolumn{4}{|c|}{ Europeans } & \multicolumn{4}{|c|}{ Polynesians } & \multicolumn{4}{|c|}{ Melanesians } \\
\hline & \multicolumn{2}{|c|}{ Cases } & \multicolumn{2}{|c|}{ Controls } & \multicolumn{2}{|c|}{ Cases } & \multicolumn{2}{|c|}{ Controls } & \multicolumn{2}{|c|}{ Cases } & \multicolumn{2}{|c|}{ Controls } \\
\hline & $\begin{array}{c}N \\
(1554)\end{array}$ & $\%$ & $\begin{array}{c}N \\
(1973)\end{array}$ & $\%$ & $\begin{array}{c}N \\
(146)\end{array}$ & $\%$ & $\begin{array}{c}N \\
(242)\end{array}$ & $\%$ & $\begin{array}{c}N \\
(155)\end{array}$ & $\%$ & $\begin{array}{c}N \\
(106)\end{array}$ & $\%$ \\
\hline \multicolumn{13}{|l|}{ Study } \\
\hline CATHY & 451 & 28.9 & 534 & 27.1 & 1 & 0.7 & & & & & & \\
\hline Cuba & 102 & 6.6 & 113 & 5.7 & & & & & & & & \\
\hline Chernobyl & 66 & 4.2 & 304 & 15.4 & & & & & & & & \\
\hline E3N & 277 & 17.8 & 287 & 14.5 & & & & & & & & \\
\hline New Caledonia & 21 & 1.3 & 70 & 3.5 & 28 & 19.2 & 55 & 22.7 & 155 & 100 & 106 & 100 \\
\hline French Polynesia & & & 4 & 0.2 & 114 & 78.1 & 181 & 74.8 & & & & \\
\hline YOUNG-thyr & 637 & 41.0 & 661 & 33.5 & 3 & 2.0 & 6 & 2.5 & & & & \\
\hline \multicolumn{13}{|l|}{ Age (years) } \\
\hline$<25$ & 272 & 17.5 & 513 & 26.0 & 0 & 0 & 0 & 0 & 0 & 0 & 0 & 0 \\
\hline $25-50$ & 763 & 49.1 & 887 & 45.2 & 113 & 77.4 & 186 & 73.3 & 89 & 57.4 & 69 & 65.1 \\
\hline$\geq \mathbf{5 0}$ & 519 & 33.4 & 573 & 29.0 & 33 & 22.6 & 56 & 26.7 & 66 & 42.6 & 37 & 34.9 \\
\hline \multicolumn{13}{|l|}{ Sex } \\
\hline Men & 275 & 17.7 & 454 & 23.0 & 14 & 9.6 & 22 & 8.6 & 9 & 5.8 & 8 & 7.5 \\
\hline Women & 1279 & 82.3 & 1519 & 77.0 & 132 & 92.4 & 220 & 91.4 & 146 & 94.2 & 98 & 92.5 \\
\hline \multicolumn{13}{|l|}{ Histology } \\
\hline Papillary & 1417 & 91.2 & & & 121 & 82.9 & & & 132 & 85.2 & & \\
\hline Follicular & 137 & 8.8 & & & 25 & 17.1 & & & 23 & 14.8 & & \\
\hline \multicolumn{13}{|l|}{$\begin{array}{l}\text { Size of carcinoma } \\
\text { (only papillary) }\end{array}$} \\
\hline$<10 \mathrm{~mm}$ & 506 & 32.6 & & & 67 & 45.9 & & & 69 & 44.5 & & \\
\hline$\geq 10 \mathrm{~mm}$ & 904 & 58.2 & & & 45 & 30.8 & & & 62 & 40.0 & & \\
\hline Missing & 144 & 9.2 & & & 34 & 23.3 & & & 24 & 15.5 & & \\
\hline
\end{tabular}

ORs associated with this allele were in the same direction in the three populations. Interestingly, we observed that the risk allele [T] was more common in Oceanians (allele frequency $=0.92$ and 0.82 in Melanesians and Polynesians, respectively) than in Europeans (allele frequency $=0.28$ ).

\section{Locus 8p12}

\section{Fine-mapping}

At locus 8p12, we replicated the previously reported associations with SNPs rs2466076 (OR = $\left.1.21, p=1.0 \times 10^{-4}\right)$ and $\mathrm{rs} 2439302(\mathrm{OR}=1.20, p=$ $\left.2.6 \times 10^{-4}\right)$ in Europeans. Furthermore, rs6996585 and rs 1254274 , identified in previous GWAS in Asians, were also associated with DTC risk in Europeans from EPITHYR $\left(\mathrm{OR}=1.21, p=1.6 \times 10^{-4}\right.$, and $\mathrm{OR}=1.22$, $p=9.8 \times 10^{-5}$ respectively) (Supplementary Table 3 ). However, none of these associations reached a genomewide significance level $\left(p<5 \times 10^{-8}\right)$. In Melanesians and in Polynesians, none of these SNPs were significant but the OR estimates for these four previously reported
SNPs were in the same direction than for the Europeans (Supplementary Table 3).

In Europeans, the strongest association was observed for the genotyped SNP rs28406305 (OR $=1.32$, $\left.p=5.9 \times 10^{-8}\right)$ and 37 SNPs were associated with DTC risk at $p<1 \times 10^{-7}$ (Supplementary Table 5). In our European sample, this variant was moderately correlated with the SNP rs6996585 highlighted in a previous GWAS [13] with pairwise $\mathrm{r}^{2}=0.35$. After conditioning the association test on the lead SNP rs28406305 (Figure 2A), no additional significant signal was observed (Figure 2B) suggesting the presence of only one causal variant within the region.

In Melanesians and Polynesians, no SNP was significantly associated with DTC (Figure 2C and 2D). The most significant association was observed for rs6989422 in Melanesians $\left(\mathrm{OR}=2.06, p=4.1 \times 10^{-3}\right)$ and for rs58964893 $\left(\mathrm{OR}=1.71, p=2.5 \times 10^{-3}\right)$ in Polynesians. In these populations, these two SNPs were not correlated with rs28406305 which was highlighted in Europeans $\left(\mathrm{r}^{2}<0.01\right)$.

The LD patterns at $8 \mathrm{p} 12$ in the three ethnic groups were similar, with larger LD blocks observed in 
Table 2: Results of colocalization analyses for SNPs with posterior probability of causality $>0.10$ at loci 2q35 and 8p12, in Europeans, Polynesians, Melanesians and all individuals

\begin{tabular}{|c|c|c|c|c|c|c|c|c|c|c|c|c|c|c|c|c|}
\hline \multirow[b]{2}{*}{ Locus } & \multirow[b]{2}{*}{ SNP } & \multirow[b]{2}{*}{ EA } & \multicolumn{4}{|c|}{ Europeans } & \multicolumn{4}{|c|}{ Polynesians } & \multicolumn{4}{|c|}{ Melanesians } & \multicolumn{2}{|c|}{ eQTL } \\
\hline & & & EAF & OR & $p$ & $\mathbf{P P}$ & EAF & OR & $p$ & PP & EAF & OR & $p$ & PP & $\mathbf{P}^{(\mathbf{b})}$ & associated gene \\
\hline \multirow[t]{2}{*}{$2 q 35$} & rs16857609 & $\mathrm{T}$ & 0.28 & 1.42 & $3.7 \times 10^{-10}$ & 0.41 & 0.82 & 1.42 & 0.12 & 0.32 & 0.92 & 1.05 & 0.88 & 0.22 & $\begin{array}{l}1.9 \times 10^{-20} \\
2.8 \times 10^{-19}\end{array}$ & $\begin{array}{c}\text { DIRC3 } \\
I G F B P 5\end{array}$ \\
\hline & rs 12990503 & $\mathrm{C}$ & 0.28 & 1.41 & $3.4 \times 10^{-10}$ & 0.39 & 0.17 & 1.48 & 0.35 & 0.35 & 0.08 & 0.90 & 0.75 & 0.39 & $\begin{array}{l}1.9 \times 10^{-20} \\
1.2 \times 10^{-19}\end{array}$ & $\begin{array}{c}\text { DIRC3 } \\
\text { IGFBP5 }\end{array}$ \\
\hline $8 \mathrm{p} 12$ & rs2439304 (a) & A & 0.50 & 1.16 & $1.7 \times 10^{-3}$ & 0.65 & 1.11 & 1.11 & 0.52 & 0.52 & 0.41 & 1.03 & 0.84 & 0.35 & $3.1 \times 10^{-39}$ & $N R G 1$ \\
\hline
\end{tabular}

EA: effect allele; EAF: effect allele frequency; OR: odds ratio; p: $p$-value; PP: posterior probability of causality. PP were derived from the colocalization analysis (using eQTL $p$-values obtained from PancanQTL database). (a) Imputed SNP, the quality score of imputation was equal to 1 for the 3 ethnic groups. (b) $P$-values of eQTLs of thyroid tumor cells from PancanQTL database.

Melanesians (Supplementary Figure 4). However, the SNPs rs2439304 and rs28406305 were located in the same LD block in Melanesians but not in Europeans nor in Polynesians.

In the pooled analysis, the most significant association was observed for the genotyped SNP rs28406305 $\left(\mathrm{OR}=1.30, p=4.1 \times 10^{-8}\right)$. After conditioning the analysis on the top SNP rs28406305, no additional SNP was highlighted (Supplementary Figures 2C and 2D).

\section{Functional data}

Using eQTL data from PancanQTL, the colocalization analysis gave the highest PP for rs2439304 in the three ethnic groups $\left(\mathrm{PP}_{\text {Europeans }}=0.65, \mathrm{PP}_{\text {Melanesians }}=\right.$ 0.52 and $\mathrm{PP}_{\text {Polynesians }}=0.35$ ) (Table 2 and Supplementary Figure 5). In these three groups, this SNP was strongly correlated with the GWAS SNP rs2439302 $\left(\mathrm{r}^{2}=1\right)$, but moderately correlated with the top SNPs $\left(r^{2}=0.50\right.$ with rs28406305 in Europeans, $r^{2}=0.40$ with rs6989422 in Melanesians and $\mathrm{r}^{2}=0.59$ with rs58964893 in Polynesians). Furthermore, this SNP was not significantly related to DTC (in Europeans: $\mathrm{OR}=1.20, p=2.6 \times 10^{-4}$; in Polynesians: $\mathrm{OR}=1.10, p=0.55$; in Melanesians: $\mathrm{OR}$ $=1.05, p=0.79$ ). Also, rs2439304 is an eQTL strongly associated with the expression of NRG1 in thyroid tumor cells with $p=3.1 \times 10^{-39}$ in PancanQTL. Rs2439304 is located in the promoter region of $N R G 1$. It alters many enhancer sites of histone modifications and markers of chromatin states in several tissues. This SNP is notably located within two markers of actively transcribed chromatin states, which are active states associated with genes' expression level in adipocytes. Rs2439304 is also located within enhancer site of epigenetic methylation to the DNA packaging protein Histone $\mathrm{H} 3$ in adipocytes.

Rs28406305, which is the top SNP in Europeans, is located within two sites of epigenetic methylation to the DNA packaging protein Histone $\mathrm{H} 3 \mathrm{H} 3 \mathrm{~K} 4 \mathrm{me} 3$ in adipocytes and liver cells. Among the top SNPs that are in the same LD block than rs28406305, rs7844425 $\left(\mathrm{r}^{2}=\right.$ $0.96, \mathrm{OR}=1.32, p=7.6 \times 10^{-8}$ ) was more likely to have a deleterious impact based on the probability score of being likely a regulatory variant calculated with RegulomeDB and the results of Haploreg V4. This SNP is located within seven sites of epigenetic methylation to $\mathrm{H} 3 \mathrm{~K} 4 \mathrm{me} 3$ in several tissues, within two sites of epigenetic acetylation to the DNA packaging Histone $\mathrm{H} 3 \mathrm{H} 3 \mathrm{~K} 27 \mathrm{ac}$, and within several markers of chromatin states in different tissues. Importantly, rs7844425 is an eQTL strongly associated with the expression of NRG1 in thyroid tissue, with $p=$ $2.3 \times 10^{-17}$ in PancanQTL. However, this SNP was not highlighted in the colocalization analysis, with very low $\mathrm{PP}$ in the three ethnic groups $\left(\mathrm{PP}_{\text {Europeans }}=8.8 \times 10^{-28}\right.$, $\mathrm{PP}_{\text {Melanesians }}=3.4 \times 10^{-27}$ and $\left.\mathrm{PP}_{\text {Polynesians }}=3.4 \times 10^{-27}\right)$.

\section{Stratified analyses}

We performed subgroup analyses for rs2439304, which had the highest PP of causality based on eQTL data, by stratifying by study, sex, age group, histology and size of the thyroid carcinoma in Europeans (Figure 3B). No heterogeneity by subgroup was observed. However, while comparing the results by ethnic groups, we observed a significant heterogeneity between these groups $\left(\mathrm{I}^{2}=\right.$ $92.3 \%, p<10^{-4}$ ). This variant was imputed with high imputation quality in all populations (info score $>0.99$ ).

We also performed subgroups analyses for rs7844425 which was the most functionally interesting SNP associated to DTC based on the results of Regulome DB and Haploreg V4. In Europeans we observed a significant heterogeneity by histological type of DTC ( ${ }^{2}$ $>81 \%, p=0.02$ ), with a positive association observed only for PTC (Figure 4).

\section{DISCUSSION}

The few GWAS conducted so far allowed the identification of several DTC susceptibility loci with the strongest associations located on $2 \mathrm{q} 35,9 \mathrm{q} 22.33,8 \mathrm{p} 12$ and 14q13.3. Published fine-mapping studies have been conducted at loci 9q22.22 and 14q13.3 [15, 16], including our previous study investigating loci 9q22.33 and 14q.13.3 in Melanesians [15], but the present study is, to our knowledge, the first study that investigates loci 2q35 and 8 p12 in details. Moreover, investigating these genomic regions not only in Europeans but also in Melanesians and Polynesians from New-Caledonia and French Polynesia is 
of particular relevance given that these populations have one of the highest incidence rates of DTC in the world. Although high parity and obesity have been associated with DTC risk in Melanesians [18, 19] and could explain a part of the elevated incidence, the remaining reasons are yet unknown. Therefore, deciphering the genetic architecture of DTC in these under-studied populations could shed new light on the susceptibility to this endocrine-related cancer.

The trans-ethnic aspect is an asset of the EPITHYR study. Indeed, it was showed that trans-ethnic metaanalyses that combine results of the same trait across genetically diverse populations can aid fine-mapping by capitalizing on ethnic differences in LD patterns [20]. The LD patterns at $2 \mathrm{q} 35$ and 8 p12 in the three ethnic groups were slightly similar although LD blocks were larger in Melanesians and Polynesians than in Europeans (Supplementary Figures 1 and 4). However, the limited sample size of the Polynesian and Melanesian populations led to a lack of power to detect associations. In order to gain statistical power, we chose to conduct a pooled analysis using LMM, so that the differences in LD patterns between the individuals were taken into account by adjusting for the genetic relationship matrix as random effect.

For the two investigated loci, association between DTC risk and the previously reported GWAS SNPS were replicated in Europeans (Supplementary Table 3). The PCA performed in Polynesians and in Melanesians using the HGDP reference panel showed that Polynesians are genetically close to East Asians (Supplementary Figure 6). Therefore, despite the lack of power, we could have expected to replicate the associations previously highlighted in Asians, among Polynesians from EPITHYR and to a lesser extend in Melanesians. At locus 8p12, although the results were not statistically significant, the reported ORs in these two populations were in the same direction than those previously reported in the Asian GWAS. However, at locus $2 \mathrm{q} 35$, the previously associated SNPs in Asian GWAS were in the same direction in Polynesians but not in Melanesians (Supplementary Table 3).
A
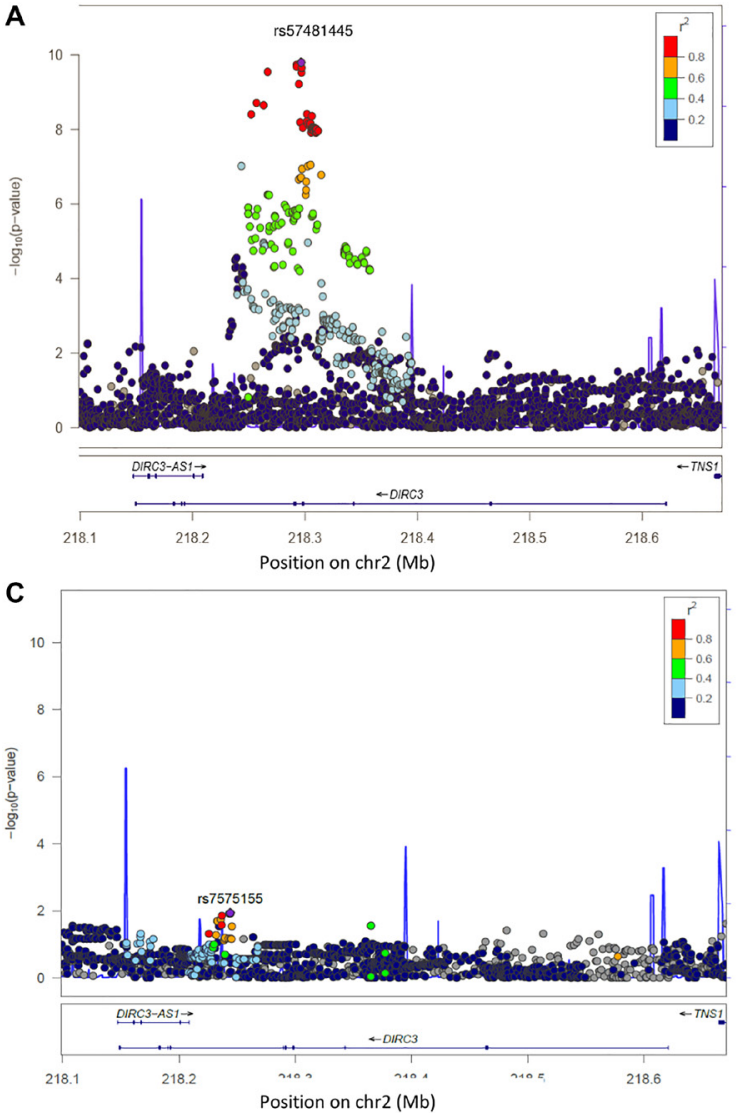

B
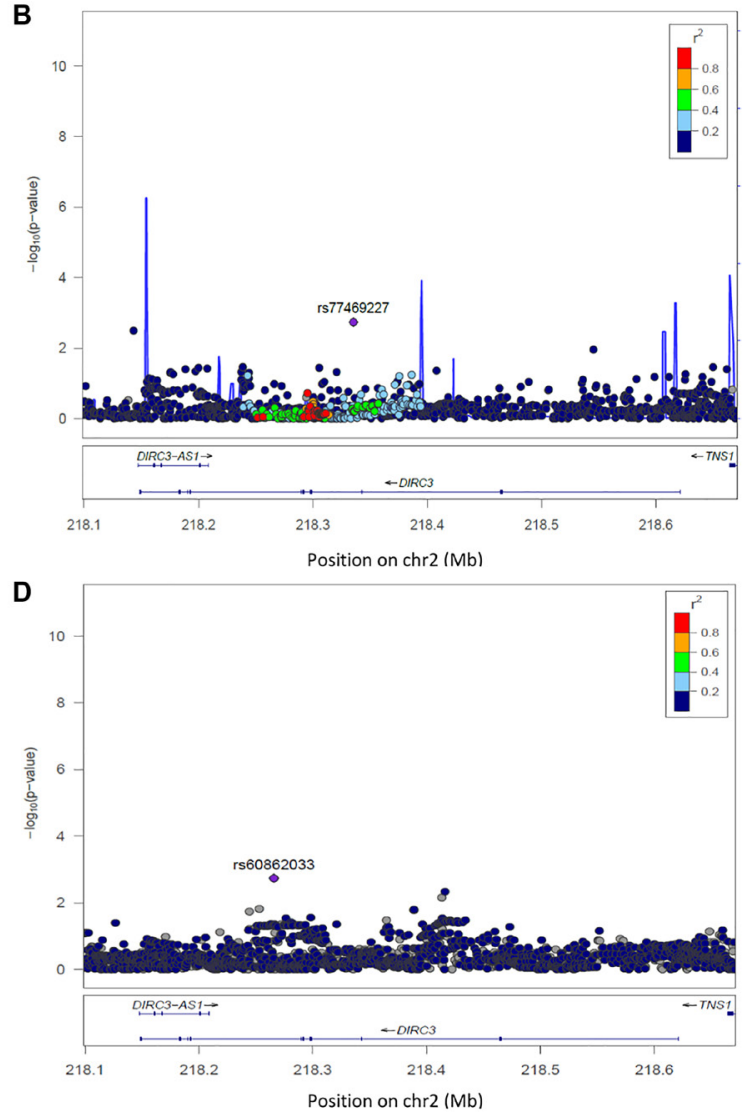

Figure 1: Regional plot of single-SNP association and conditional regression at locus 2 q35 in Europeans, Melanesians and Polynesians. On Y axis, are the $-\log 10$ ( $p$-value); on X axis, the position of SNPs and genes on the chromosome. The color of each SNP spot reflects its $\mathrm{r}^{2}$ with the most associated SNP (in purple). The correlation between SNP is ranged from high (in red) to low (in blue). Grey dots correspond to missing variants (imputed SNPs with no genotype with probability $>0.9)$. (A) Plot of - $\log 10$ ( $p$-values) of SNP association results at locus $2 \mathrm{q} 35$ in Europeans. (B) Plot of $-\log 10$ ( $p$-values) of SNP association results at locus 2 q35 in Europeans, after conditioning the test on SNP rs57481445. (C) Plot of $-\log 10$ ( $p$-values) of SNP association results at locus 2q35 in Melanesians. (D) Plot of $-\log 10 p$-values of SNP association results at locus $2 \mathrm{q} 35$ in Polynesians. 
In Europeans, the conditional analysis showed that the association of DTC risk with the top SNP rs57481445 was correlated with other SNPs within the region, suggesting that only one independent signal lies at 2q35. Our analyses pinpointed rs16857609 as a possible causal SNP for this region in Europeans, Melanesians and Polynesians. This SNP was strongly associated with the expression of the two nearby genes DIRC3 and IGFBP5 in thyroid tumour cells, according to TCGA data. Insulinlike growth factors (IGFs) play a pivotal role in tissue homeostasis, regulating cell proliferation, differentiation and migration during development and also in adulthood. Since it was shown that IGFBP5 is overexpressed in PTC, it could have a proliferative effect on thyroid tumour cells [21]. We found that rs 16857609 is located within different methylation sites involving histone H3 in many tissues. Also, this SNP is located within many regulatory elements (chromatin state linked to an enhancer, histone modifications in DNA methylation or acetylation) that control genes expression in adipose nuclei tissue and in adipocyte stem cells. Since obesity has been consistently associated with an increased risk of TC in epidemiological studies [3], these observations support the hypothesis that rs16857609 could play a role in the aetiology of DTC via complex obesity-associated pathways. The frequency of the risk allele [T] is much higher in Oceanians than in Europeans and this could explain a part of the highest incidence of DTC observed in the former populations if the association is confirmed. Interestingly, rs16857609 has been associated with increased breast cancer risk in Europeans [22]. Since IGFBP5 is a physiological regulator of epithelial cell survival in the mammary gland [23], it was proposed that a deregulation of IGFBP5 expression induced by variants located upstream of DIRC3 [24] could lead to the development of a breast tumour. Altogether, the link between rs 16857609, breast cancer risk and IGFBP5 on one side, and the link between TC and IGFBP5 on the other suggests that a deregulation of IGFBP5 expression
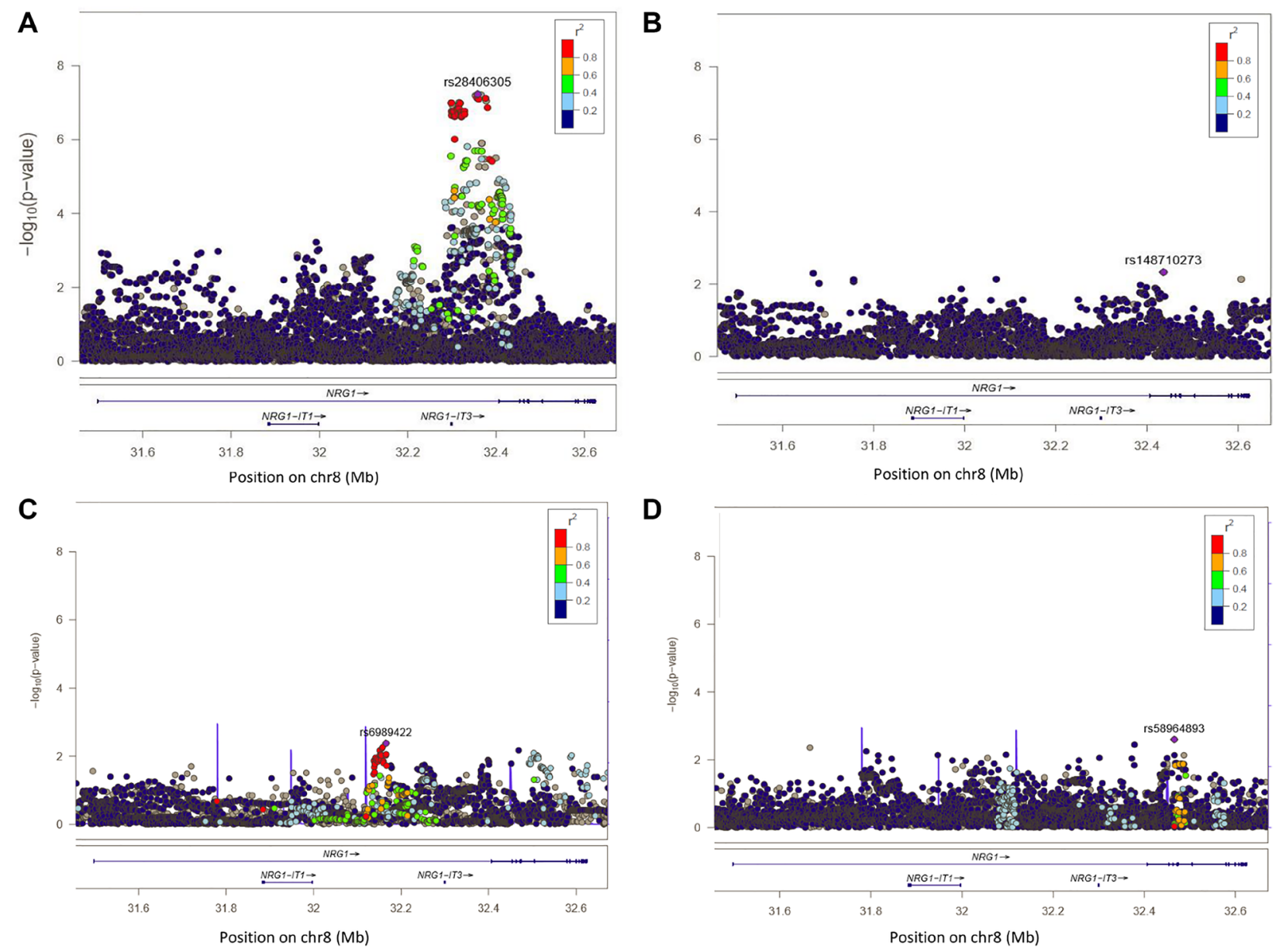

Figure 2: Regional plot of single-SNP association and conditional regression at locus 8 p12 in Europeans, Melanesians and Polynesians. On Y axis, are the $-\log 10$ ( $p$-value); on X axis, the position of SNPs and genes on the chromosome. The color of each SNP spot reflects its $r^{2}$ with the most associated SNP (in purple). The correlation between SNP is ranged from high (in red) to low (in blue). Grey dots correspond to missing variants (imputed SNPs with no genotype with probability $>0.9$ ). (A) Plot of $-\log 10$ ( $p$-values) of SNP association results at locus 8p12 in Europeans. (B) Plot of $-\log 10$ ( $p$-values) of SNP association result rs28406305 at locus 8p12 in Europeans, after conditioning the test on SNP rs28406305. (C) Plot of $-\log 10$ ( $p$-values) of SNP association results at locus 8p12 in Melanesians. (D) Plot of $-\log 10$ ( $p$-values) of SNP association results at locus 8 p12 in Polynesians. 
may also lead to the proliferation of thyroid cells and eventually to PTC development.

The conditional analysis at locus 8p12 in Europeans revealed a single association signal. Among the most associated SNPs, we reported rs7844425 as the variant which is the most likely to have a functional deleterious impact. This SNP is located in the upstream transcript region of the major isoforms of the NRG1 gene expressed in human thyroid tissue and thyroid cell lines, namely NM 004495, NM 013958 and NM 001160008. The gene encodes a membrane glycoprotein that mediates cell-cell signalling and plays a critical role in the growth and development of multiple organ systems. Rs 7844425 is predicted to alter conserved elements involved in the regulation of NRG1 expression. To our knowledge, no previous GWAs highlighted rs7844425 or other SNPs from our study located in the same LD block. Interestingly, this SNP is strongly correlated with rs17716295 in Europeans $\left(\mathrm{r}^{2}=0.93\right)$ which was associated with antipsychotic treatment response in schizophrenia patients [25] and it was recognized that disturbances in the balance of thyroid hormones contribute to mental status deregulation recognized that thyroid dysfunction is associated with psychiatric disorders, with a higher proportion of hypothyroidism among patients with schizophrenia [26]. We found that rs7844425 is only moderately correlated

A

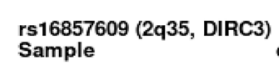

EUR
CATHY
YT
E3N
CHER
CUBA
NC-POL

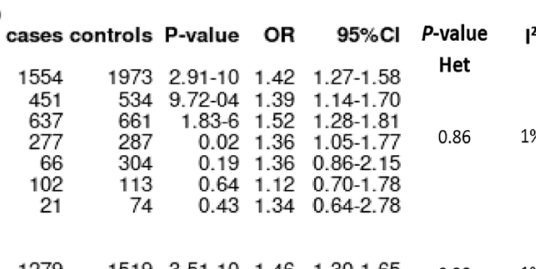

sex
Women

Mon

age

Age $\geq 50$
Age $<50$

histology

Follicular (All)

carcinoma size

Papillary (micro)

ethnic group

EUR (EAF=0.28)

MEL $(E A F=0.92)$
POL (EAF $=0.82)$

$\begin{array}{rrrrrrr}1279 & 1519 & 3.51-10 & 1.46 & 1.30-1.65 & 0.28 & 1 \% \\ 275 & 454 & 0.01 & 1.35 & 1.06-1.72 & & \end{array}$

$\begin{array}{rrrrrrr}520 & 569 & 0.01 & 1.31 & 1.08-1.59 & & \\ 1034 & 1404 & 2.51-09 & 1.49 & 1.31-1.70 & 0.55 & 12.6 \%\end{array}$

$\begin{array}{rrrrrrr}1417 & 1973 & 3.92-11 & 1.45 & 1.30-1.61 & & \\ 137 & 1973 & 0.31 & 1.15 & 0.87-1.52 & <10^{-4} & 99.2 \%\end{array}$

$\begin{array}{llll}973 & 0.31 & 1.15 & 0.87-1.52\end{array}$

904

$\begin{array}{llll}1973 & 6.41-09 & 1.46 & 1.29-1.66\end{array}$

$\begin{array}{llll}1973 & 2.33-06 & 1.45 & 1.24-1.69\end{array}$

$\begin{array}{rrrrr}1554 & 1973 & 2.92-10 & 1.42 & 1.27-1.58 \\ 142 & 98 & 0.88 & 1.05 & 0.54-2.04\end{array}$

$\begin{array}{lllll}138 & 230 & 0.13 & 1.40 & 0.91-2.16\end{array}$

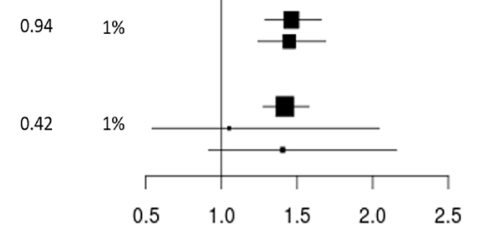

B
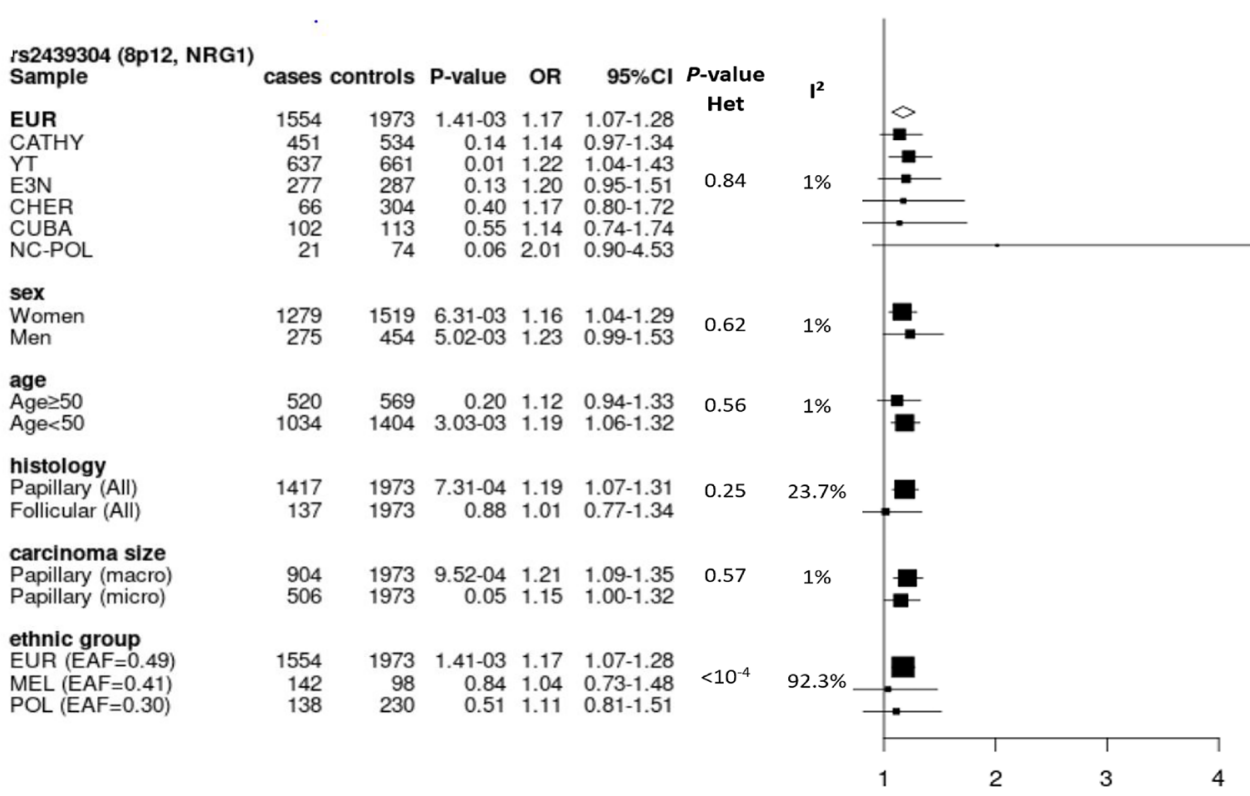

Figure 3: Forest plots of subgroup analyses for rs16857609 (A) and rs2439304 (B), by study, sex, age group, histology and size of carcinoma in Europeans, and by ethnic group in the entire dataset. (A) Result for the genotyped SNP rs16857609 in DIRC3 at 2q35 (Effect allele (T) frequency in Europeans: 0.28). (B) Result for the imputed SNP rs2439304 in NRG1 at 8p12 (Effect allele (A) frequency in Europeans: 0.49). EAF: effect allele frequency; EUR: Europeans; MEL: Melanesians; POL: Polynesians; Het: heterogeneity. 
with rs2439304 that we also highlighted at the locus 8p12 $\left(r^{2}=0.51\right.$ in European). Although rs2439304 was not significantly associated with DTC in our populations (OR $=1.2, p=0.001$ in Europeans), it had the highest PP of causality in the three ethnic groups using eQTL data at 8p12. Rs2439304 is strongly correlated with rs2439302 which was reported in a previous GWAS on DTC risk [27] $\left(\mathrm{r}^{2}=1\right)$. Both SNPs are located within a $32 \mathrm{~kb}$ LD block in intron 1 of NRG1. By performing haplotype analysis of this LD block, He et al. proposed that the impact of several risk alleles on transcriptional regulation is probably combinatorial in dictating $N R G 1$ expression and in conferring susceptibility to DTC. Furthermore, by using CHIP-seq experiment and luciferase assay in primary thyroid cell culture, they showed that the risk allele of rs2439304 and the risk allele of rs2439302 increase expression of all three major NRG1 isoforms when comparing with the wild type allele. This result is in line with the eQTL analysis conducted by Son et al. suggesting that the increased expression of NRG1 in thyroid tissue might influence the development or progression of TC [13] but do not support results by Gudmundsson et al. who reported that carriers of rs2439302 risk allele have a lower expression of NRG1 [9].

For both SNPs, rs7844425 and rs16857609, we performed analyses restricted to PTC as sensitivity tests but results did not differed significantly from the overall analysis so we chose not to present these results (data not shown).
In summary, we confirmed the previously associated SNPs in Europeans and in Asians at loci 2q35 and 8p12, and our fine-mapping approach identified new potential causal SNPs at each locus (rs16857609 at locus 2q35, rs7844425 and rs2439304 at locus 8p12) to be prioritized for functional studies.

\section{MATERIALS AND METHODS}

\section{Study populations and genotyping}

We used GWAS data from the EPITHYR consortium that included subjects from seven case-control studies: three were conducted in Metropolitan France (CATHY [28], YOUNG-thyr [29] and E3N [30] studies), two in South Pacific Islands [19, 31], one in Cuba [32] and one in the Gomel region of Belarus, affected by the Chernobyl accident [33]. Study protocols were approved by the local ethic committees and written informed consent was obtained from all participants. Genotyping was conducted using the Infinium Oncoarray-500k Beadchip (Illumina) [34] comprising about 500,000 SNPs to which we incorporated 13,759 additional custom markers involved in TC or thyroid hormones metabolism. Details of the participating studies [19, 28-32, 35] and quality controls (QC) of the genotyping were described in detail previously [14]. QC and ethnicity definition were similar to those described by the OncoArray consortium [34].
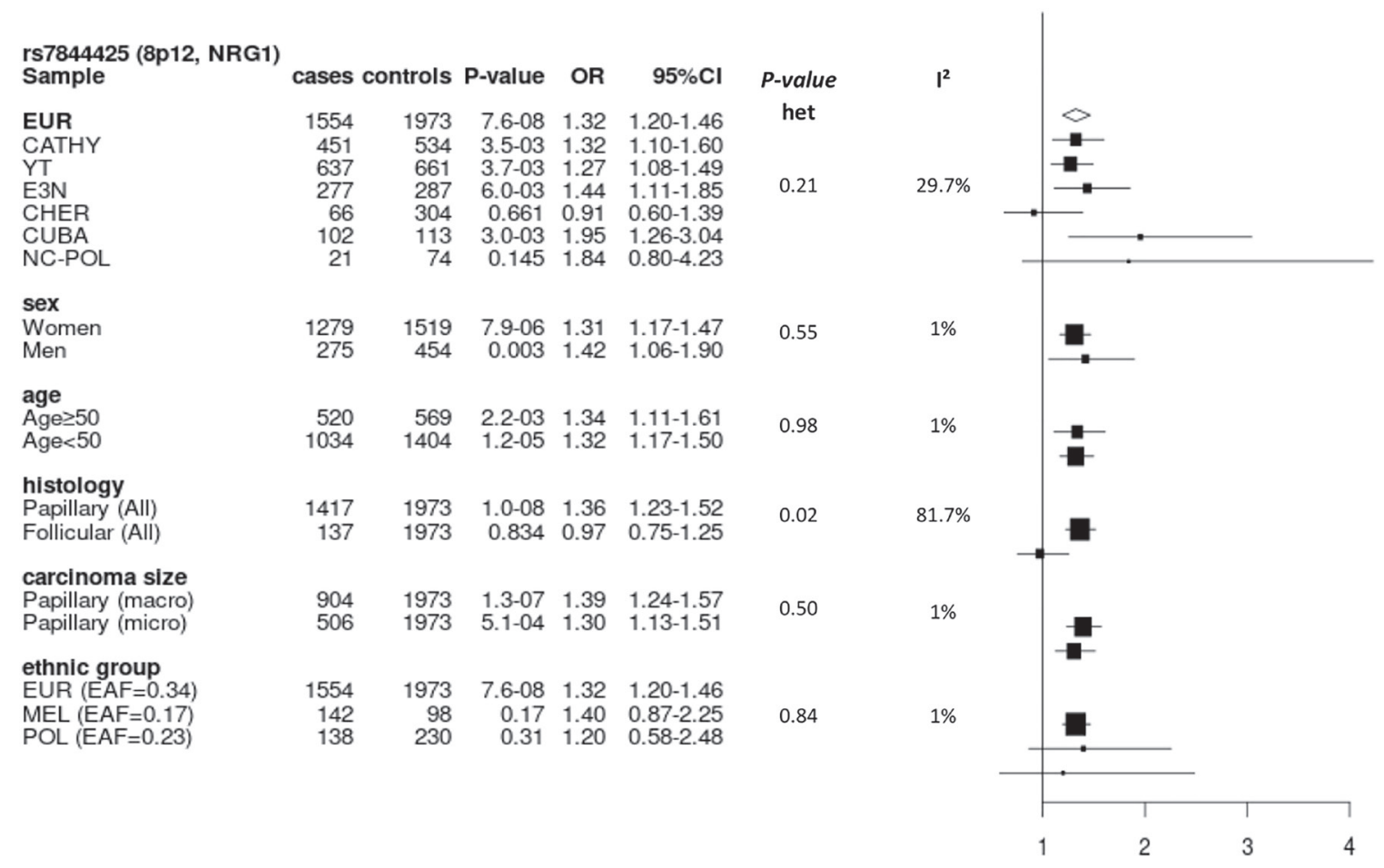

Figure 4: Forest plot of subgroup analyses for rs7844425 stratifying on study, sex, age group, histology and size of carcinoma in Europeans, and stratifying on population group in the entire dataset. Result for the imputed SNP rs7844425 in $N R G 1$ at 8p12 (Effect allele (A) frequency in Europeans: 0.34). EAF: effect allele frequency; EUR: Europeans; MEL: Melanesians; POL: Polynesians; Het: heterogeneity. 
After QC, we analysed data from 3,527 Europeans (1,554 cases/1,973 controls) and 649 Asians (301 cases/348 controls). Asian participants came mostly from Polynesia and New-Caledonia so we renamed this group as Oceanians. In order to compare this population to other reference panel, we conducted a principal component analysis (PCA) using the Human Genome Diversity Panel (HGDP) [36]. We observed that Polynesians were closest to East Asian population whereas Melanesians were closest to the Oceanian population (which was from Bougainville). Based on this PCA (Supplementary Figure 6), we separated Oceanian participants into the Melanesian (155 cases/106 controls) and Polynesian subgroups (146 cases/242 controls) in order to reduce the heterogeneity in this population.

\section{SNP selection}

\section{At locus 2q35}

For the current study, we defined a mapping interval of $162,680 \mathrm{bp}$ at $2 \mathrm{q} 35(218,231,649-218,394,329$; NCBI build 37 assembly) that included SNPs in the same linkage disequilibrium (LD) block as the two GWAS SNPs, rs966423 and rs6759952 (i.e. SNPs with $\mathrm{r}^{2}>0.2$ ) according to the 1000 Genomes Project (phase 1 CEU) [37]. We first catalogued 299 SNPs correlated with one of the two GWAS SNPs at $r^{2}>0.2$ and with a minor allele frequency (MAF) greater than 0.02 in Europeans according to the 1000 Genomes Project. We added a set of SNPs to tag the remaining SNPs of the region with MAF $>0.02$ and $r^{2}>0.8$ by forcing these 299 SNPs and SNPs that were already on the chip. A total of 398 unique tag SNPs were identified of which 226 SNPs were not in the initial design of the chip and were therefore added for genotyping.

As the mapping region was entirely included within the DIRC3 gene, we chose to extend the region to analyse to $50 \mathrm{~kb}$ upstream and downstream from the gene boundaries ( $572 \mathrm{~kb}$, positions 218,098,746-218,671,316; NCBI build 37 assembly).

Finally, 452 SNPs were genotyped for this region, and 441 of them passed QC in Europeans and in Oceanians (Melanesians and Polynesians). These genotypic data were used to impute the non-genotyped SNPs using IMPUTEv2 [37] and the 1000 Genomes Project (phase 3 ) as the reference panel [37]. For the imputation in Oceanian individuals, we added the 26 Oceanians from Simons Genome Diversity Panel (SGDP, phase 3) [38] to the 1000 Genomes reference panel. All monomorphic imputed SNPs were excluded and only imputed SNPs with an imputation quality score above 0.3 were kept in the analyses. Hence, the analysis of the 2 q35 locus was based on 452 genotyped SNPs and 2,230 imputed SNPs in Europeans, 441 genotyped SNPs and 2053 imputed SNPs in Polynesians, and 441 genotyped SNPs and 1,484 imputed SNPs in Melanesians.

\section{At locus 8p12}

Similarly, at $8 \mathrm{p} 12$, the region to be enriched was defined based on the LD block containing rs2439302 (positions 32,158,293-32,641,727; NCBI build 37 assembly). We added 492 SNPs to the design of the chip in this region.

As this region, which included the three previously identified SNPs (rs2439302, rs6996585 and rs2466076), is located within the NGR1 gene, we extended the analysis to all SNPs located $50 \mathrm{~kb}$ upstream and downstream from this gene boundaries $(1,215 \mathrm{~kb} ; 31,456,820-32,672,558$; NCBI build 37 assembly).

Thus, the analysis of the $8 \mathrm{p} 12$ locus was based on 552 genotyped SNPs and 5,941 imputed SNPs in Europeans, 497 genotyped SNPs and 5,316 imputed SNPs in Polynesians, and 497 genotyped and 3,728 imputed SNPs in Melanesians.

\section{Statistical analyses}

Imputed SNPs were analysed as expected genotype count (gene dosage). Odds ratios (OR) and 95\% confidence interval (CI) testing the single marker association with DTC were calculated using the logistic mixed model (LMM) with the genetic relationship matrix as random effect to account for population structure and cryptic relatedness [39]. All analyses were adjusted for age, sex and study and were stratified by ethnic group. A pooled analysis was also performed with Europeans, Melanesians and Polynesians using the corresponding genetic relationship matrix as a random effect in the LMM. These analyses were performed using Gaston $\mathrm{R}$ package [40]. LD between variants was calculated from the imputed data with PLINK (v1.9), using the genotype with a probability higher than 0.9 . Otherwise, genotypes were missing for the SNP.

For some variants of interest, we also conducted stratified analysis by study, age group, sex and histology. Heterogeneity of odds ratios across the stratification groups was assessed by using Cochran $Q$ test and $\mathrm{I}^{2}$ index [41].

For each locus, we first performed conditional analysis in order to test for residual association after accounting for a lead SNP, which permits to make an assumption about the number of independent signals within the region.

\section{Functional annotation}

To assess the possible functional effect of the associated SNPs, several annotation databases with different features were interrogated. We were mainly interested in features involved in regulatory aspects of gene expression including gene promoters, enhancers, transcription factor binding sites (TFBS), untranslated 
regions (UTR), DNase I hypersensitive sites (DHSs) and histone modifications.

We annotated gene promoter regions and UTR using Gene Elements of GenCode [42], and enhancer elements using FANTOM5 [43] and Roadmap collections [44]. Enhancers are short regions of DNA playing a key role in the transcription of genes by increasing the likelihood that transcription of a particular gene will occur. We also used annotations of super-enhancers available in the catalogue by Hnisz et al. [45]. These elements consist of large clusters of transcriptional enhancers driving expression of genes that define cell identity. We used TFBS database [46] for annotations of TFBS and retrieved annotation of DNase I hypersensitive sites (DHSs) from three sources: Roadmap and maps of human DHS sites as defined by Thurman et al. [47] and by Maurano et al [48]. DHSs are regions of chromatin functionally related to transcriptional activity and are sensitive to cleavage by the DNase I enzyme. Finally, we used chromatin state annotation from the Roadmap database.

To investigate noncoding variants, we also used the following freely available tools, RegulomeDB [49] (https:// regulomedb.org/regulome-search/) and Haploreg V4 (http:// www.broadinstitute.org/mammals/haploreg). These tools predict whether a given SNP may alter the regulatory protein binding sites, chromatin structure and histone modifications.

In addition, expression Quantitative Trait Locus (eQTL) information was used to perform a colocalization analysis within each genomic region using the Coloc $\mathrm{R}$ package [50]. This Bayesian method allows to assess whether two related traits share a causal variant by calculating a posterior probability of causality (PP) for each SNP. For this analysis, we used results of the association test between each SNP and DTC risk and results of the association test between each SNP and gene expression in thyroid tumour cells that are publicly available in the PancanQTL database [17]. PancanQTL obtained the gene expression profiles from The Cancer Genome Atlas (TCGA) (http://cancergenome.nih.gov/ abouttcga). In Europeans, among the 2,682 tested variants at locus 2q35, 564 were cis-eQTLs, that is, an eQTL that acts in (locally) to a gene. At locus 8p12, among the 6,493 tested variants, 736 were cis-eQTLs.

\section{Abbreviations}

DHS: DNase I hypersensitive sites; DTC: differentiated thyroid carcinoma; eQTL: expression quantitative trait locus; FTC: follicular thyroid carcinoma; GWAS: genome-wide association study; LD: linkage disequilibrium; LMM: logistic mixed model; MAF: minor allele frequency; OR: odds ratio; PCA: principal component analysis; PP: posterior probability; PTC: papillary thyroid carcinoma; PY: person-year; QC: quality control; SNP: single nucleotide polymorphism; TC: thyroid cancer; TFBS: transcription factor binding site;
TSH: thyroid stimulating hormone; UTR: untranslated region.

\section{Author contributions}

Project supervision: FL and TT. Selection of add-ons on the Oncoarray chip: TT, FL, CX, CR, FDV. Quality controls and data management: by JG, MK. Genotyping was supervised and carried out by $\mathrm{DB}, \mathrm{CB}, \mathrm{AB}$ and JFD. Bioinformatics analyses were performed by JG, MK, OK, PES. Statistical analyses were carried out by JG, PES. Subjects recruitment, biological material collection and handling was organized and carried out by FDV, PG, CS, AVG, CM, PLP, MCB, AK, EO, RMO, CX, YR, CR, FR, EA, TT. JG, FL and TT drafted the manuscript. All authors reviewed the manuscript and approved the final version of the paper.

\section{CONFLICTS OF INTEREST}

Authors have no conflicts of interest to declare.

\section{FUNDING}

This work was supported by the Institut National du Cancer (Inca grant 9533), the Fondation ARC pour la Recherche sur le Cancer (ARC grant PGA120150202302), the Centre National de Recherche en Génomique Humaine, CEA, Electricité de France (conseil scientifique de Radioprotection d'EDF, grant EP 2019-01), Fondation de France (Grant 2016-70074) and Plan Cancer (Project ThyrGenRad, Grant ENV201415). The E3N cohort received support from the MGEN, Gustave Roussy and Ligue contre le cancer for its set up and maintenance. The E3N cohort was also supported by a state grant from the Agence Nationale pour la Recherche (ANR, grant number ANR-10-COHO-0006) within the Investissement d'Avenir program; and from Ministère de l'enseignement supérieur, de la recherche et de l'innovation (MESRI, grant number 2102 918823). JG was the recipient of a PhD fellowship from Région Ile-de-France.

\section{REFERENCES}

1. IARC. Thyroid fact sheet, Globocan 2018. 2018. https:// gco.iarc.fr/today/data/factsheets/cancers/.

2. Truong T, Rougier Y, Dubourdieu D, GuihenneucJouyaux C, Orsi L, Hémon D, Guénel P. Time trends and geographic variations for thyroid cancer in New Caledonia, a very high incidence area (1985-1999). Eur J Cancer Prev. 2007; 16:62-70. https://doi.org/10.1097/01. cej.0000236244.32995.e1.

3. Lauby-Secretan B, Scoccianti C, Loomis D, Grosse Y, Bianchini F, Straif K. Body fatness and cancer - Viewpoint of the IARC working group. N Engl J Med. 2016; 375: 794-8. https://doi.org/10.1056/NEJMsr1606602. [PubMed] 
4. Lee JH, Hwang Y, Song RY, Yi JW, Yu HW, Kim SJ, Chai YJ, Choi JY, Lee KE, Park SK. Relationship between iodine levels and papillary thyroid carcinoma: A systematic review and meta-analysis. Head Neck. 2017; 39:1711-8. https:// doi.org/10.1002/hed.24797. [ [PubMed]

5. Caini S, Gibelli B, Palli D, Saieva C, Ruscica M, Gandini S. Menstrual and reproductive history and use of exogenous sex hormones and risk of thyroid cancer among women: a meta-analysis of prospective studies. Cancer Causes Control. 2015; 26:511-8. https://doi.org/10.1007/s10552015-0546-z. [PubMed]

6. Hemminki K, Eng C, Chen B. Familial Risks for Nonmedullary Thyroid Cancer. J Clin Endocrinol Metab. 2005; 90:57. https://doi.org/10.1210/jc.2005-0935. [PubMed]

7. Gudmundsson J, Sulem P, Gudbjartsson DF, Jonasson JG, Sigurdsson A, Bergthorsson JT, He H, Blondal T, Geller F, Jakobsdottir M, Magnusdottir DN, Matthiasdottir S, Stacey SN, et al. Common variants on $9 \mathrm{q} 22.33$ and $14 \mathrm{q} 13.3$ predispose to thyroid cancer in European populations. Nat Genet. 2009; 41:460-4. https://doi.org/10.1038/ng.339. [PubMed]

8. Takahashi M, Saenko VA, Rogounovitch TI, Kawaguchi T, Drozd VM, Takigawa-Imamura H, Akulevich NM, Ratanajaraya C, Mitsutake N, Takamura N, Danilova LI, Lushchik ML, Demidchik YE, et al. The FOXE1 locus is a major genetic determinant for radiation-related thyroid carcinoma in Chernobyl. Hum Mol Genet. 2010; 9:2516. https://doi.org/10.1093/hmg/ddq123. [PubMed]

9. Gudmundsson J, Sulem P, Gudbjartsson DF, Jonasson JG, Masson G, He H, Jonasdottir A, Sigurdsson A, Stacey SN, Johannsdottir H, Th Helgadottir H, Li W, Nagy R, et al. Discovery of common variants associated with low TSH levels and thyroid cancer risk. Nat Genet. 2012; 44:319-22. https://doi.org/10.1038/ng.1046. [PubMed]

10. Köhler A, Chen B, Gemignani F, Elisei R, Romei C, Figlioli G, Cipollini M, Cristaudo A, Bambi F, Hoffmann P, Herms S, Kalemba M, Kula D, et al. Genome-Wide Association Study on Differentiated Thyroid Cancer. J Clin Endocrinol Metab. 2013; 98:E1674-81. https://doi.org/10.1210/ jc.2013-1941. [PubMed]

11. Figlioli G, Köhler A, Chen B, Elisei R, Romei C, Cipollini M, Cristaudo A, Bambi F, Paolicchi E, Hoffmann P, Herms S, Kalemba M, Kula D, et al. Novel Genome-Wide Association Study-Based Candidate Loci for Differentiated Thyroid Cancer Risk. Sci Rep. 2014; 5:1-7. https://doi. org/10.1210/jc.2014-1734. [ubMed]

12. Gudmundsson J, Thorleifsson G, Sigurdsson JK, Stefansdottir L, Jonasson JG, Gudjonsson SA, Gudbjartsson DF, Masson G, Johannsdottir H, Halldorsson GH, Stacey SN, Helgason H, Sulem $\mathrm{P}$, et al. A genome-wide association study yields five novel thyroid cancer risk loci. Nat Commun. 2017; 8:6-13. https://doi.org/10.1038/ncomms14517. [PubMed]

13. Son HY, Hwangbo Y, Yoo SK, Im SW, Yang SD, Kwak SJ, Park MS, Kwak SH, Cho SW, Ryu JS, Kim J, Jung YS, Kim TH, et al. Genome-wide association and expression quantitative trait loci studies identify multiple susceptibility loci for thyroid cancer. Nat Commun. 2017; 8:15966. https://doi.org/10.1038/ncomms15966.

14. Truong T, Lesueur F, Sugier P, Guibon J, Xhaard C, Karimi M, Kulkarni O, Lucotte E, Guizard A, Ren Y, Adjadj E. Multiethnic genome-wide association study of differentiated thyroid cancer in the EPITHYR consortium. Int J Cancer. 2021 Feb 2. https://doi.org/10.1002/ijc.33488. [Epub ahead of print].

15. Tcheandjieu C, Lesueur F, Sanchez M, Baron-Dubourdieu D, Guizard AV, Mulot C, Laurent-Puig P, Schvartz C, Truong T, Guenel P. Fine-mapping of two differentiated thyroid carcinoma susceptibility loci at 9q22.33 and $14 q 13.3$ detects novel candidate functional SNPs in Europeans from metropolitan France and Melanesians from New Caledonia. Int J Cancer. 2016; 139:617-27. https://doi. org/10.1002/ijc.30088. [PubMed]

16. Jendrzejewski J, Liyanarachchi S, Eiterman A, Thomas A, He H, Nagy R, Senter L, Sworczak K, de la Chapelle A. Fine mapping of $14 q 13$ reveals novel variants associated with different histological subtypes of papillary thyroid carcinoma. Int J Cancer. 2019; 144:503-12. https://doi. org/10.1002/ijc.31933. [PubMed]

17. Gong J, Mei S, Liu C, Xiang Y, Ye Y, Zhang Z, Feng J, Liu R, Diao L, Guo AY, Miao X, Han L. PancanQTL: Systematic identification of cis -eQTLs and trans -eQTLs in 33 cancer types. Nucleic Acids Res. 2018; 46:D971-6. https://doi.org/10.1093/nar/gkx861. [PubMed]

18. Truong T, Orsi L, Dubourdieu D, Rougier Y, Hémon D, Guénel P. Role of goiter and of menstrual and reproductive factors in thyroid cancer: A population-based case-control study in New Caledonia (South Pacific), a very high incidence area. Am J Epidemiol. 2005; 161:1056-65. https://doi.org/10.1093/aje/kwi136. [PubMed]

19. Guignard R, Truong T, Rougier Y, Baron-Dubourdieu D, Guénel P. Alcohol drinking, tobacco smoking, and anthropometric characteristics as risk factors for thyroid cancer: a countrywide case-control study in New Caledonia. Am J Epidemiol. 2007; 166:1140-9. https://doi. org/10.1093/aje/kwm204. [PubMed]

20. Li YR, Keating BJ. Trans-ethnic genome-wide association studies: advantages and challenges of mapping in diverse populations. Genome Med. 2014; 6:91. https://doi. org/10.1186/s13073-014-0091-5. [PubMed]

21. Stolf BS, Carvalho AF, Martins WK, Runza FB, Brun M, Hirata R, Neves EJ, Soares FA, Postigo-Dias J, Kowalski LP, Reis LFL. Differential expression of IGFBP-5 and two human ESTs in thyroid glands with goiter, adenoma and papillary or follicular carcinomas. Cancer Lett. 2003; 191:193-202. https://doi.org/10.1016/S0304-3835(02)00679-1.

22. Michailidou K, Hall P, Gonzalez-Neira A, Ghoussaini M, Dennis J, Milne RL, Schmidt MK, Chang-Claude J, Bojesen SE, Bolla MK, Wang Q, Dicks E, Lee A, et al. Large-scale genotyping identifies 41 new loci associated with breast cancer risk. Nat Genet. 2013; 45:353-61. https:// doi.org/10.1038/ng.2563. [PubMed] 
23. Marshman E. Insulin-like growth factor binding protein 5 and apoptosis in mammary epithelial cells. J Cell Sci. 2003; 116:675-82. https://doi.org/10.1242/jcs.00263. [PubMed]

24. Wyszynski A, Hong C, Lam K, Michailidou K, Lytle C, Yao S, Zhang Y, Bolla MK, Wang Q, Dennis J, Hopper JL, Southey MC, Schmidt MK, et al. An intergenic risk locus containing an enhancer deletion in 2q35 modulates breast cancer risk by deregulating IGFBP5 expression. Hum Mol Genet. 2018; 25:3863-76. https://doi.org/10.1093/hmg/ ddw223. [PubMed]

25. Jajodia A, Kaur H, Kumari K, Kanojia N, Gupta M, Baghel R, Sood M, Jain S, Chadda RK, Kukreti R. Evaluation of genetic association of neurodevelopment and neuroimmunological genes with antipsychotic treatment response in schizophrenia in indian populations. Mol Genet Genomic Med. 2016; 4:18-27. https://doi.org/10.1002/ mgg3.169. [PubMed]

26. Sharif K, Tiosano S, Watad A, Comaneshter D, Cohen AD, Shoenfeld Y, Amital H. The link between schizophrenia and hypothyroidism: a population-based study. Immunol Res. 2018; 66:663-6. https://doi.org/10.1007/s12026-018-90307. [PubMed]

27. He H, Li W, Liyanarachchi S, Wang Y, Yu L, Genutis LK, Maharry S, Phay JE, Shen R, Brock P, De La Chapelle A. The Role of NRG1 in the Predisposition to Papillary Thyroid Carcinoma. J Clin Endocrinol Metab. 2018; 103:1369-79. https://doi.org/10.1210/jc.2017-01798. [PubMed]

28. Cordina-Duverger E, Leux C, Neri M, Tcheandjieu C, Guizard AV, Schvartz C, Truong T, Guénel P. Hormonal and reproductive risk factors of papillary thyroid cancer: A population-based case-control study in France. Cancer Epidemiol Biomarkers Prev. 2017; 48:78-84. https://doi. org/10.1016/j.canep.2017.04.001. [PubMed]

29. Xhaard C, De Vathaire F, Cléro E, Maillard S, Ren Y, Borson-Chazot F, Sassolas G, Schvartz C, Colonna M, Lacour B, Danzon A, Velten M, Marrer E, et al. Original Contribution Anthropometric Risk Factors for Differentiated Thyroid Cancer in Young Men and Women From Eastern France: A Case-Control Study. Am J Epidemiol. 2015; 182:202. https://doi.org/10.1093/aje/kwv048. [PubMed]

30. Clavel-Chapelon F, Guillas G, Tondeur L, Kernaleguen C, Boutron-Ruault MC. Risk of differentiated thyroid cancer in relation to adult weight, height and body shape over life: The French E3N cohort. Int J Cancer. 2010; 126:2984-90. https://doi.org/10.1002/ijc.25066. [PubMed]

31. Brindel P, Doyon F, Rachédi F, Boissin JL, Sebbag J, Shan L, Chungue V, Bost-Bezeaud F, Petitdidier P, Paoaafaite J, Teuri J, de Vathaire F. Anthropometric factors in differentiated thyroid cancer in French Polynesia: a case-control study. Cancer Causes Control. 2009; 20:581-90. https://doi. org/10.1007/s10552-008-9266-y. [PubMed]

32. Lence-Anta JJ, Xhaard C, Ortiz RM, Kassim H, Pereda CM, Turcios S, Velasco M, Chappe M, Infante I, Bustillo M, García A, Clero DF, Maillard S, et al. Environmental, Lifestyle, and Anthropometric Risk Factors for
Differentiated Thyroid Cancer in Cuba: A Case-Control Study. Eur Thyroid J. 2014; 3:189-96. https://doi. org/10.1159/000362928. [PubMed]

33. Stezhko VA, Buglova EE, Danilova LI, Drozd VM, Krysenko NA, Lesnikova NR, Minenko VF, Ostapenko VA, Petrenko SV, Polyanskaya ON, Rzheutski VA, Tronko MD, Bobylyova OO, et al. A Cohort Study of Thyroid Cancer and Other Thyroid Diseases after the Chornobyl Accident: Objectives, Design and Methods. Radiat Res. 2004; 161:481-92. https://doi.org/10.1667/3148. [PubMed]

34. Amos CI, Dennis J, Wang Z, Byun J, Schumacher FR, Gayther SA, Hunter DJ, Sellers TA. The OncoArray Consortium: a Network for Understanding the Genetic Architecture of Common Cancers. Cancer Epidemiol Biomarkers Prev. 2017; 26:126-35. https://doi.org/10.1038/ ncomms5234.SUMO1.

35. Lonjou C, Damiola F, Moissonnier M, Durand G, Malakhova I, Masyakin V, Le Calvez-Kelm F, Cardis E, Byrnes G, Kesminiene A, Lesueur F. Investigation of DNA repair-related SNPs underlying susceptibility to papillary thyroid carcinoma reveals MGMT as a novel candidate gene in Belarusian children exposed to radiation. BMC Cancer. 2017; 17:328. https://doi.org/10.1186/s12885-017-3314-5. [PubMed]

36. Cavalli-Sforza LL. The Human Genome Diversity Project: past, present and future. Nat Rev Genet. 2005; 6:333-40. https://doi.org/10.1038/nrg1596. [PubMed]

37. Howie B, Marchini J, Stephens M. Genotype Imputation with Thousands of Genomes. G3 (Bethesda). 2011; 1:4577. https://doi.org/10.1534/g3.111.001198. [PubMed]

38. Mallick S, Li H, Lipson M, Mathieson I, Gymrek M, Racimo F, Zhao M, Chennagiri N, Nordenfelt S, Tandon A, Skoglund P, Lazaridis I, Sankararaman S, et al. The Simons Genome Diversity Project: 300 genomes from 142 diverse populations. Nature. 2016; 538:201-6. https://doi. org/10.1038/nature18964. [PubMed]

39. Chen H, Wang C, Conomos MP, Stilp AM, Li Z, Sofer T, Szpiro AA, Chen W, Brehm JM, Celedó JC, Redline S, Papanicolaou GJ, Thornton TA, et al. Control for Population Structure and Relatedness for Binary Traits in Genetic Association Studies via Logistic Mixed Models. Am J Hum Genet. 2016; 98:653. https://doi.org/10.1016/j. ajhg.2016.02.012. [PubMed]

40. Perdry H, Dandine-Roulland C, Banddyopadhyay D, Kettner L. Gaston: Genetic Data Handling (QC, GRM, LD, PCA) \& Linear Mixed Models. CRAN. 2018.

41. Higgins JP, Thompson SG. Quantifying heterogeneity in a meta-analysis. Stat Med. 2002; 21:1539-58. https://doi. org $/ 10.1002 /$ sim.1186. [PubMed]

42. Harrow J, Frankish A, Gonzalez JM, Tapanari E, Diekhans M, Kokocinski F, Aken BL, Barrell D, Zadissa A, Searle S, Barnes I, Bignell A, Boychenko V, et al. GENCODE: The reference human genome annotation for the ENCODE project. Genome Res. 2012; 22:1760-74. https://doi. org/10.1101/gr.135350.111. [PubMed] 
43. Andersson R, Gebhard C, Miguel-Escalada I, Hoof I, Bornholdt J, Boyd M, Chen Y, Zhao X, Schmidl C, Suzuki T, Ntini E, Arner E, Valen E, et al. An atlas of active enhancers across human cell types and tissues. Nature. 2014; 507:455-61. https://doi.org/10.1038/nature12787. [PubMed]

44. Roadmap Epigenomics Consortium, Kundaje A, Meuleman W, Ernst J, Bilenky M, Yen A, Heravi-Moussavi A, Kheradpour P, Zhang Z, Wang J, Ziller MJ, Amin V, Whitaker JW, et al. Integrative analysis of 111 reference human epigenomes. Nature. 2015; 518:317-29. https://doi. org/10.1038/nature14248. [PubMed]

45. Hnisz D, Abraham BJ, Lee TI, Lau A, Saint-André V, Sigova AA, Hoke H, Young RA. Transcriptional superenhancers connected to cell identity and disease. Cell. 2013; 155:934-47. https://doi.org/10.1016/j.cell.2013.09.053. [PubMed]

46. Yang JH, Li JH, Jiang S, Zhou H, Qu LH. ChIPBase: A database for decoding the transcriptional regulation of long non-coding RNA and microRNA genes from ChIP-Seq data. Nucleic Acids Res. 2013; 41:D177-87. https://doi. org/10.1093/nar/gks1060. [PubMed]
47. Thurman RE, Rynes E, Humbert R, Vierstra J, Maurano MT, Haugen E, Sheffield NC, Stergachis AB, Wang H, Vernot B, Garg K, John S, Sandstrom R, et al. The accessible chromatin landscape of the human genome. Nature. 2012; 489:75-82. https://doi.org/10.1038/nature11232. [PubMed]

48. Maurano MT, Humbert R, Rynes E, Thurman RE, Haugen E, Wang H, Reynolds AP, Sandstrom R, Qu H, Brody J, Shafer A, Neri F, Lee K, et al. Systematic localization of common disease-associated variation in regulatory DNA. Science (80-). AAAS. 2012; 337:1190-5. https://doi. org/10.1126/science.1222794. [PubMed]

49. Boyle AP, Hong EL, Hariharan M, Cheng Y, Schaub MA, Kasowski M, Karczewski KJ, Park J, Hitz BC, Weng S, Cherry JM, Snyder M. Annotation of functional variation in personal genomes using RegulomeDB. Genome Res. 2012; 22:1790-7. https://doi.org/10.1101/gr.137323.112. [PubMed]

50. Giambartolomei C, Vukcevic D, Schadt EE, Franke L, Hingorani AD, Wallace C, Plagnol V. Bayesian Test for Colocalisation Between Pairs of Genetic Association Studies Using Summary Statistics. PLoS Genet. 2014; 10:e100. 